\title{
UNDERBODY MAINTENANCES UNIT AMBULAN MASJID DI WILAYAH KOTA BANJARMASIN
}

\author{
Muhammad Firdaus Jauhari ${ }^{1}$, Raihan ${ }^{2}$, Muhammad Arsyad ${ }^{3}$, Rusmini Sri Maryati ${ }^{4}$ \\ Politeknik Negeri Banjarmasin ${ }^{1,2,3,4}$ \\ firdaus.jauhari@poliban.ac.id ${ }^{l}$
}

\begin{abstract}
The underbody maintenance of the mosque ambulance unit aims to provide maintenance services for the lower part of the vehicle for the mosque's ambulance unit which has been routinely used for social services so that it can extend the service period of the unit. The method of implementing this activity is divided into 3 stages: pre-activity, implementation of activities, and monitoring after the activities are carried out. Maintenance includes hose and fuel pipe, hose and brake pipe, engine oil leakage, engine coolant leak, front and rear suspension, front suspension and arm, steering gear case, steering rack boot \& tie rod end, an exhaust line, transmission oil manually. After underbody maintenance, the ambulance condition was better than before. Some of the treatments carried out also include changing parts such as oil and nitrogen gas for mosque ambulance tires. So that the ambulance unit is better prepared to provide services to the wider community.
\end{abstract}

Keywords: underbody, maintenance, ambulance, mosque

\begin{abstract}
ABSTRAK
Kegiatan underbody maintenance unit ambulan masjid bertujuan untuk memberikan pelayanan perawatan bagian bawah kendaraan bagi unit ambulan masjid yang selama ini rutin digunakan untuk pelayanan sosial, sehingga dapat memperpanjang masa pelayanan unit tersebut. Metode pelaksanaan kegiatan ini terbagi dalam 3 tahapan: pra-kegiatan, pelaksanaan kegiatan, dan monitoring setelah kegiatan dilaksanakan. Perawatan meliputi bagian selang dan pipa saluran bahan bakar, selang dan pipa rem, kebocoran oli mesin, kebocoran engine coolant, suspensi depan dan belakang, suspensi depan dan arm, steering gear case, steering rack boot \& tie rod end, saluran buang, oli transmisi manual. Setelah dilakukan perawatan underbody maintenance, kondisi ambulan jadi lebih baik daripada sebelumnya. Beberapa perawatan yang dilakukan juga meliputi pergantian part seperti oli dan gas nitrogen untuk ban ambulan masjid. Sehingga unit ambulan lebih siap untuk memberikan pelayanan kepada masyarakat luas.
\end{abstract}

Kata Kunci: bawah bodi, perawatan, ambulan, masjid

\section{PENDAHULUAN}

Penggunaan ambulan sebagai unit layanan sosial dalam hal transportasi gawat darurat medis atau keperluan lainnya cukup memiliki peran penting dimasyarakat. Ambulan adalah kendaraan transportasi gawat darurat medis khusus orang sakit atau cedera yang digunakan untuk membawanya dari satu tempat ke tempat lain guna perawatan lebih lanjut. Istilah ambulan digunakan untuk menerangkan kendaraan yang digunakan untuk membawa peralatan medis kepada pasien di luar rumah sakit atau memindahkan pasien ke rumah sakit untuk perawatan lebih lanjut. Kendaraan ini dilengkapi dengan sirene dan lampu berwarna merah 
dan biru gawat darurat agar dapat menembus kemacetan lalu lintas. Ambulan masjid di kota Banjarmasin juga memiliki fungsi serupa, selain untuk pelayanan transportasi gawat medis, ambulan masjid pada umumnya juga digunakan sebagai mobil pengantar jenazah. Karena lebih banyak untuk melayani keperluan sosial maka porsi perawatan kendaraan kadang tidak mendapat perhatian yang serius. Supaya kegiatan pelayanan sosial dengan ambulan masjid tetap dapat berjalan lancar maka Program Studi Teknik Otomotif Politeknik Negeri Banjarmasin berinsiatif memberikan perawatan gratis untuk unit ambulan masjid yang meliputi perawatan engine dan chasis dengan fokus pada bagian underbody.

Bagian bawah atau yang sering disebut sebagai underbody mobil, merupakan area yang sering sekali dilupakan. Hal ini memang wajar, dikarenakan area ini cukup tersembunyi, dan membutuhkan usaha lebih untuk memeriksanya. Bagian bawah atau underbody mobil merupakan area yang biasanya luput dari perhatian. Akan tetapi bagian underbody adalah area yang cukup penting untuk dilakukan pemeriksaan secara rutin. Pada area ini terdapat komponen yang menunjang stabilitas, kenyamanan, keamanan anda dalam berkendara. Banyak komponen yang wajib diperiksa pada bagian underbody mobil. Oleh karenanya kegiatan pengabdian kepada masyarakat ini cukup penting untuk dilaksanakan, mengingat kepentingan sosial yang besar oleh ambulan masjid sehingga memperpanjang masa pelayanan unit tersebut.

\section{METODE KEGIATAN / SOLUSI / TEKNOLOGI /}

Pelaksanaan kegiatan ini terbagi dalam 3 tahapan: pra-kegiatan, pelaksanaan kegiatan, dan monitoring setelah kegiatan dengan uraian sebagai berikut:

a. Tahapan pra-kegiatan, meliputi: melakukan survey dan koordinasi dengan mitra, membentuk panitia kecil (task force) untuk mengatur pelaksanaan kegiatan di lapangan, mengundang dan mengonfirmasi kehadiran.

b. Tahapan pelaksanaan, meliputi: menyelenggarakan underbody maintenances yang terdiri dari cek keadaan bodi, cek kebocoran, cairan, potensi karat, kelonggaran baut, keretakan selang karet, kekendoran karet atau bushing, kebocoran shock absorber, ban cadangan.

c. Tahapan monitoring, berupa pemantauan hasil kegiatan dalam 3 bulan setelah kegiatan perawatan dilakukan. Tahap ini memungkinkan untuk dilakukan rework jika masih terdapat gangguan atau kerusakan pada item kegiatan underbody maintenances. 


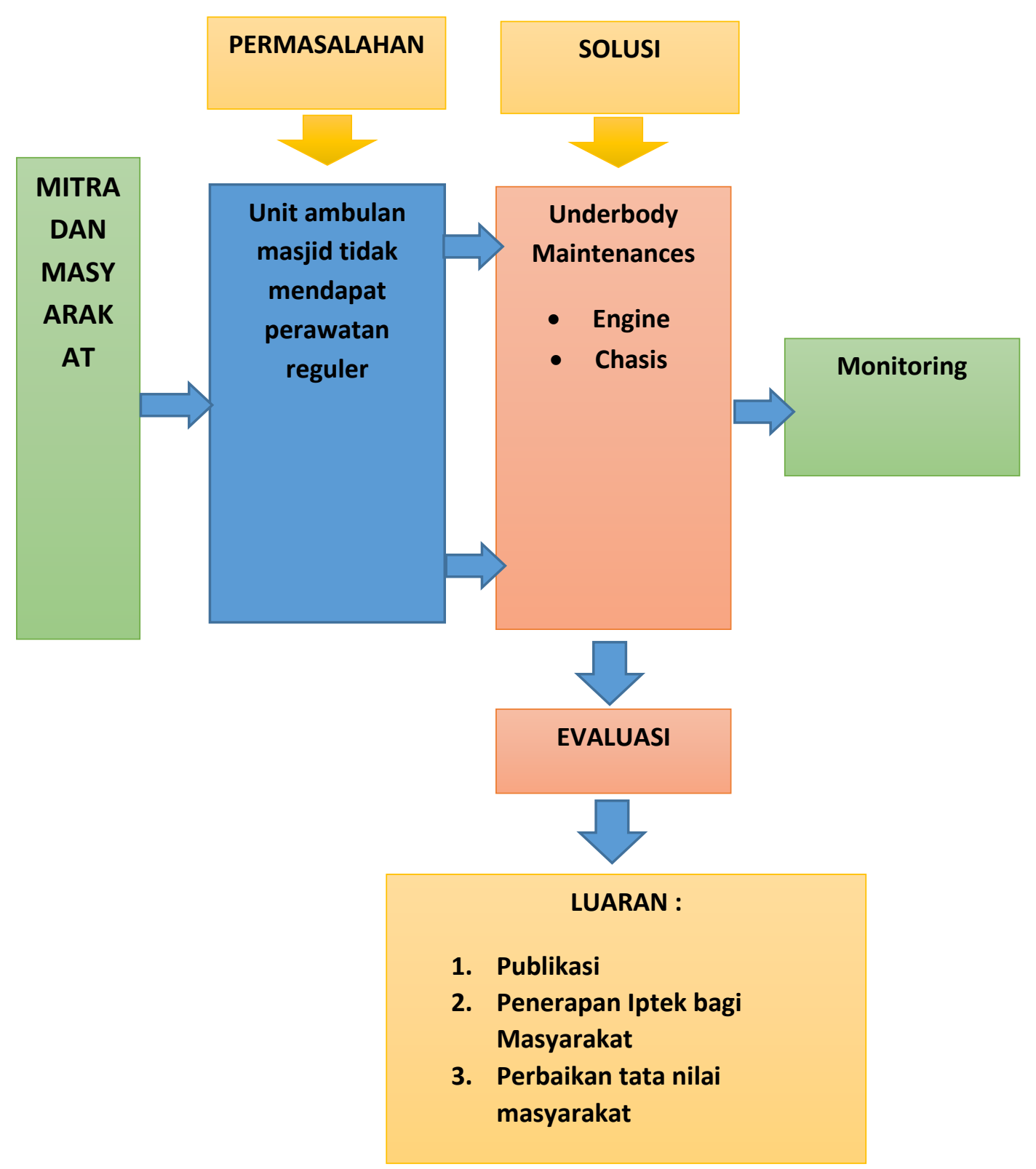

\section{HASIL DAN PEMBAHASAN}

Kegiatan Pengabdian Kepada Masyarakat ini didahului dengan survey pendahuluan. Dari hasil survey pendahuluan dan informasi yang didapat bahwa banyak unit ambulan masjid yang tidak mendapatkan perawatan secara berkala karena tidak adanya anggaran dari masjid untuk melakukan perawatan unit ambulan. Perawatan dilakukan secara incidental apabila ada terdapa kerusakan saja. Pada kegiatan ini dipilih dua buah ambulan masjid yang terdekat dengan Politeknik Negeri Banjarmasin, yaitu masjid Al Barqah dan Masjid Hasanuddin Majedi. 
Kegiatan pengabdian yang dilakukan fokus pada pemeriksaan dan perbaikan bagian bawah ambulan. Meliputi bagian bagian selang dan pipa saluran bahan bakar, selang dan pipa rem, kebocoran oli mesin, kebocoran engine coolant, suspensi depan dan belakang, suspensi depan dan arm, steering gear case, steering rack boot $\&$ tie rod end, saluran buang, oli transmisi manual.

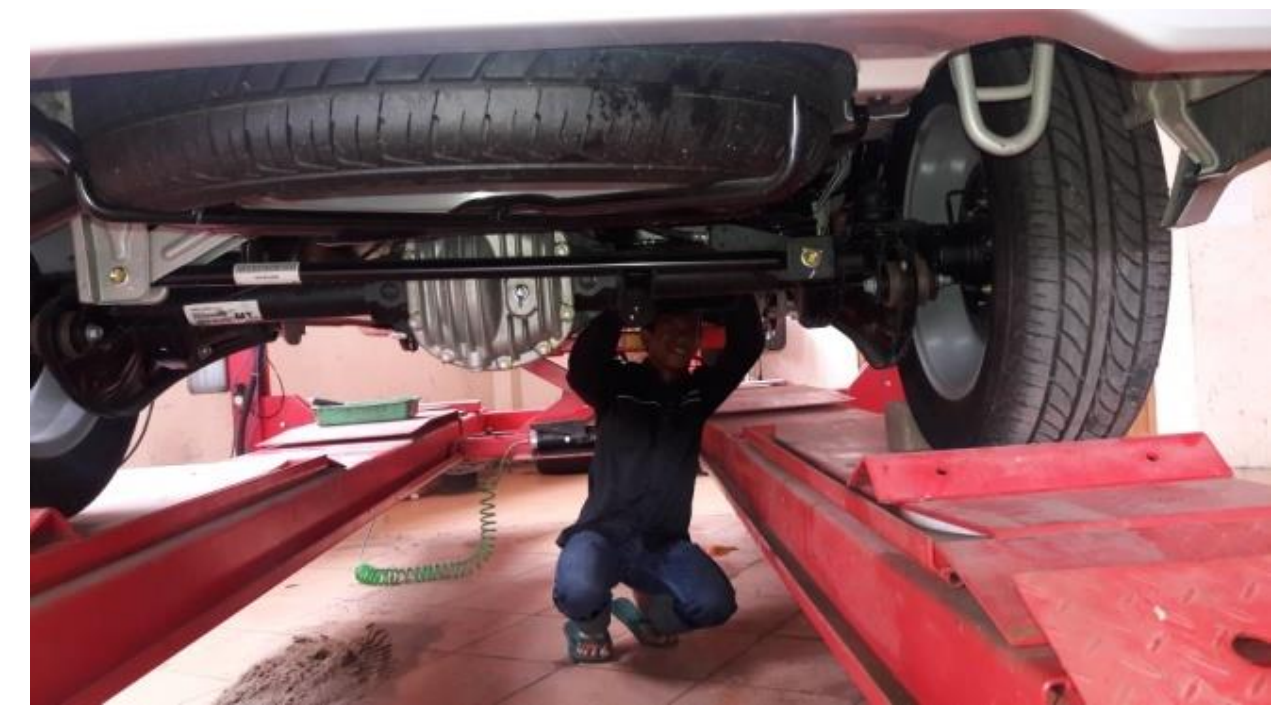

Gambar 1. Perawatan Underbody Area

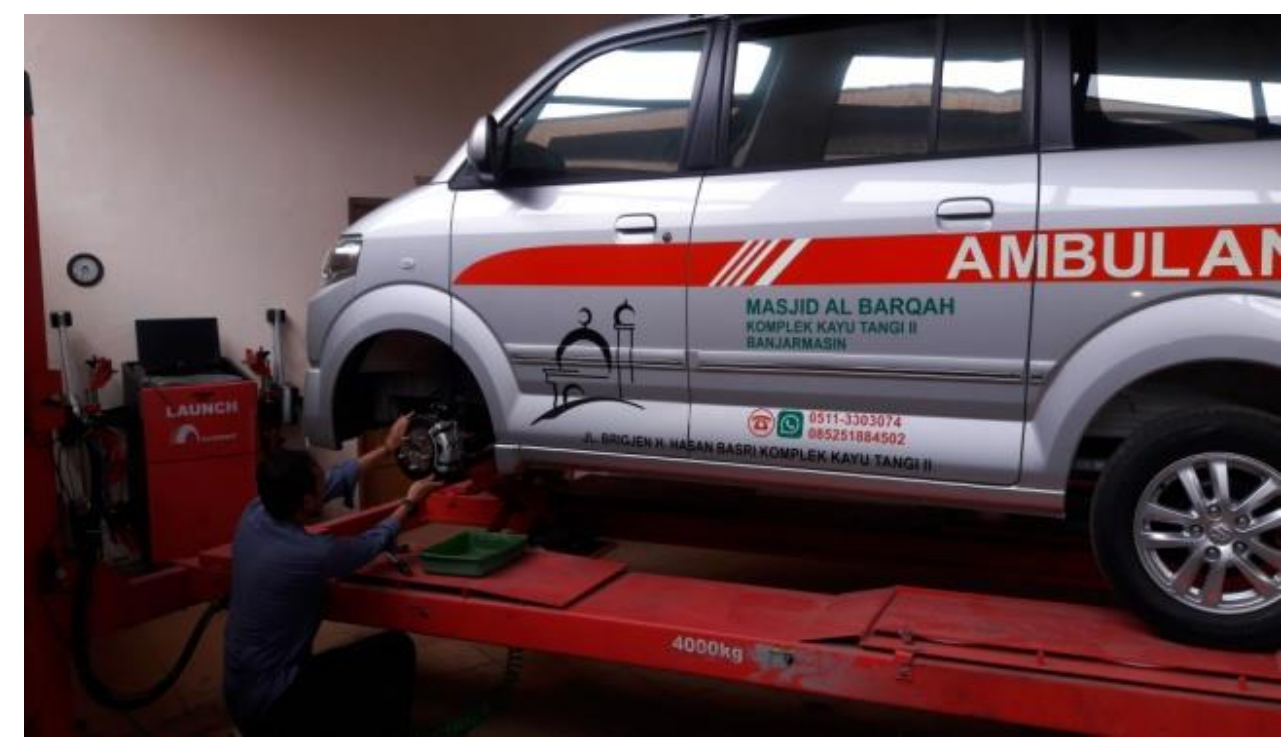

Gambar 2. Perawatan Rem Cakram

Setelah dilakukan perawatan underbody maintenance, kondisi ambulan jadi lebih baik daripada sebelumnya. Beberapa perawatan yang dilakukan juga meliputi pergantian part seperti oli dan gas nitrogen untuk ban ambulan masjid. Sehingga unit ambulan lebih siap untuk memberikan pelayanan kepada masyarakat luas. Berdasarkan tanya jawab dan pengamatan langsung selama 
kegiatan pengabdian kepada masyarakat ini memberikan hasil capaian sebagai berikut :

1. Perawatan unit ambulan menjadikan ambulan menjadi lebih baik dari segi tampilan, kondisi engine, kondisi bagian bawah kendaraan, kebersihan, dan juga kenyamanan.

2. Meningkatkan kesiapsediaan unit ambilan dalam memberikan pelayanan social kepada masyarakat luas..

3. Meningkatkan kerjasama kemitraan dan manfaat antara Politeknik Negeri Banjarmasin dengan lembaga ibadah dan social kemasyarakatan.

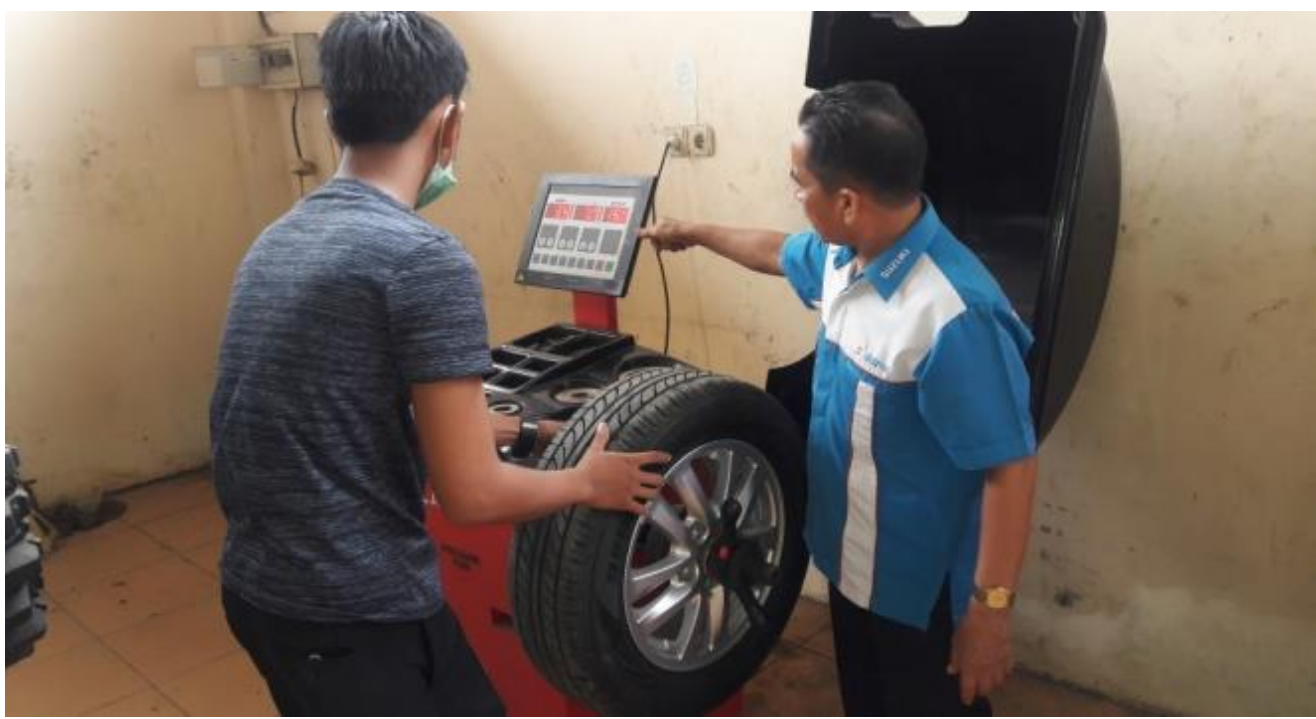

Gambar 3. Spooring dan Balancing

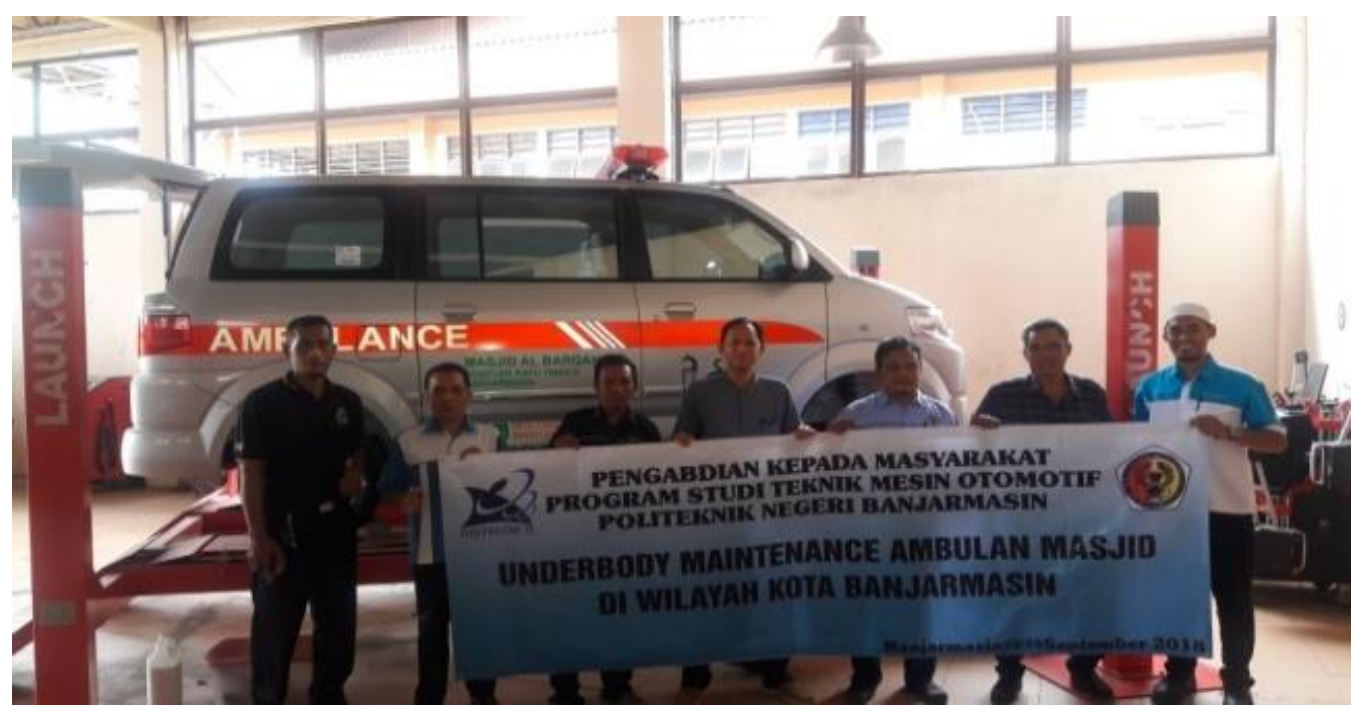


Gambar 4. Tim Pelaksana Pengabdian Kepada Masyarakat

Kegiatan pengabdian underbody maintenance unit ambulan masjid di wilayah kota Banjarmasin ini mendapat sambutan yang cukup baik. Para pengelola masjid menunjukkan minat dan antusiasme kegiatan pengabdian kepada masyarakat ini. Kegiatan berjalan dengan lancar selama pelaksanaan dan tidak ada hambatan yang berarti. Diharapkan dengan hasil pengabdian ini pihak pengelola masjid dapat memberikan pelayanan sosial kemasyarakatan yang lebih baik lagi.

\section{KESIMPULAN}

Dari hasil kegiatan pengabdian kepada masyarakat dengan kegiatan underbody maintenance unit ambulan masjid di wilayah kota Banjarmasin didapatkan peningkatan kondisi chasis dan engine untuk unit ambulan masjid, sehingga kinerja unit jadi lebih maksimal. Selain itu, peningkatan kinerja unit juga meningkatan pelayanan sosial kemasyarakatan lewat pelayanan ambulan masjid untuk dua masjid di Banjarmasin yaitu masjid Al Barqah dan masjid Hasanuddin Majedi. Diharapkan kegiatan ini memperat kerjasama dan kemitraan antara Politeknik Negeri Banjarmasin dengan lembaga ibadah dan sosial di daerah Banjarmasin Utara.

\section{DAFTAR PUSTAKA}

Pedoman Pelaksanaan Penelitian dan Pengabdian Kepada Masyarakat, Pusat Penelitian dan Pengabdian Kepada Masyarakat 2018, Politeknik Negeri Banjarmasin

Tom Denton. 2004. Automobile Electrical and Electronic Systems. Third Edition. Oxford: Charon Tec Pvt. Ltd

Toyota Motor Sales Co. Ltd. 2000. Engine Repair Manual

PT. Suzuki Indomobil Sales. 2015. Pedoman Pemeriksaan Rem. Technical Training 4W

PT. Suzuki Indomobil Sales. 2015. Pedoman Pemeriksaan Bagian Bawah Kendaraan (Under Body). Technical Training 4W 